ISSN 1676-3742

\title{
A Criação e a Questão Ecológica no Pensamento de Jürgen Moltmann
}

\author{
Maria Freire da Silva
}

\section{Resumo}

O presente artigo tem como objetivo apresentar as contribuições do pensamento de Jürgen Moltmann no que se refere à situação ecológica e à ética da criação. As relações entre teologia e ciência, na época moderna, se caracterizam por uma notável tensão, com referência à origem do universo, o que constitui um tema central no mundo da ciência. O objetivo de Moltmann é mostrar que a doutrina ecológica da criação parte de uma imaginação messiânica do futuro, onde a libertação das pessoas está em comunhão com a natureza, salvando-as do negativo, da força da morte. Seu pensamento se desenvolve articulando o problema ecológico e a criação em perspectiva trinitária.

Palavras-chave: Criação, Ecologia, Relação, Evolução.

\section{Abstract}

This article aims to present the contributions of Jürgen Moltmann's thought related to the ecological condition and the ethics of creation. The relationship between theology and science in the modern era is characterized by a remarkable tension, with reference to the origin of the universe, which is a central issue in the world of science. Moltmann's aim is to show that the ecological doctrine of creation begins on a messianic imagination of the future, where the liberation of people is in communion with nature, saving 
them from the negative force of death. His thought is developed linking the ecological problem with the creation in Trinitarian perspective.

Keywords: Creation, Ecology, Relationship, Evolution.

\section{Introdução}

No cenário mundial, o que mais vêm chamando a atenção da sociedade são as notícias acerca do Aquecimento Global. Sem dúvida, a questão ecológica se tornou o centro das atenções mundiais, mais precisamente, a temática ambiental, relacionada à crise dos anos 70 agravada nos anos 80 . Fala-se de hiperconflito, hiperimpério e por último de hiperdemocracia, hiperinteligência como ondas do futuro. Diante dessa realidade se faz a pergunta: o que a teologia tem a dizer, quais são as relevâncias teológicas capazes de iluminar a reflexão sobre a crise ambiental?

O teólogo Jürgen Moltmann situado nesse contexto percebeu que a relação viva de uma sociedade moderna com o ambiente natural é caracterizado pelas técnicas humanas, mediante as quais os humanos buscam os meios de sustentação. As técnicas, a ciência têm se desenvolvido a partir da determinação e interesses humanos sem uma vinculação com a sustentabilidade da vida do planeta, da questão ecológica. No entanto, para isso, faz-se necessário encetar um processo de conversão inserindo a compreensão do ser imagem e semelhança de Deus. Em segundo lugar é de grande relevância a re-descoberta do Deus trinitário, em suas relações de unidade e comunhão, capaz de incluir as relações humanas em toda sua complexidade.

Moltmann desenvolveu a doutrina da criação vinculada à ideia de uma doutrina ecológica da criação em perspectiva trinitária. Dessa forma, esta visão não parte de Deus como sujeito absoluto, e o mundo como objeto de sua criação, conservação e salvação, mas, seu ponto de partida, é entender Deus na consciência de seu Espírito e por causa de Cristo, como o Deus trino apresenta a comunhão única e plena em seu mistério de amor Portanto, sendo uma doutrina da criação em perspectiva ecológica, tem como pressuposto o abandono do pensamento analítico com suas distinções sujeito-objeto para buscar um modo novo de pensar, comunicativo e integrativo. $\mathrm{O}$ denominado pensar integrativo e integral, ganha relevância na aplicação de uma comunitarização entre pessoas e a natureza. 
O termo natureza é aplicado enquanto meio ambiente natural e à própria corporalidade. Postula-se a definição da vida em vários níveis: a) nível jurídico e político - a vida como uma aliança com a natureza. b) nível medicinal - a vida simbiótica, definida como totalidade psicossomática da pessoa em confronto consigo mesma. c) nível religioso - a vida enquanto comunhão de criação. Aqui, propõe-se uma doutrina ecológica com método não unidimensional, mas aberto, capaz de empregar múltiplos acessos à comunhão da criação. A tradição teológica da doutrina da criação é assumida criticamente, já que se priorizam métodos novos pós-críticos e científicos, articulando a denominada imaginação criativa em perspectiva do futuro.

\section{Criação e ecologia}

Apresenta-se, uma doutrina cristã da criação, enquanto o ser-cristão articula-se ao ser-messiânico numa concepção do mundo à luz do messias Jesus e os aspectos do tempo messiânico ${ }^{1}$. Esta doutrina messiânica da criação compreende a criação junto com o seu futuro, como morada de Deus ${ }^{2}$. As tradições bíblicas são interpretadas, mostrando a criação orientada para sua salvação em conexão com o sábado, visto como a festa da criação ${ }^{3}$, e ponto de chegada de sua plenitude ${ }^{4}$ como a prefiguração do mundo futuro ${ }^{5}$. A criação é vista à luz do seu futuro, da glória de Deus ${ }^{6}$.

O sábado, o sétimo dia da criação, atribuído ao descanso de Deus, aponta para o ano sabático na história de Israel no qual seriam restabelecidas as relações de igualdade ${ }^{7}$. Esta ideia busca fundamentos na vida pública de Jesus

\footnotetext{
${ }^{1}$ Moltmann, J. Gott in der Schöpfung, 19; Metz, J.B. Christliche Anthropozentrik, über die Denkform des Thomas von Aquinn, München, 1962.pp. 68-69.

${ }^{2}$ Moltmann, J. Op.cit., 19. Retoma-se a idéia de que desde os tempos mais remotos, o futuro da criação, era designado como sendo Reino de glória. O que quer indicar, uma criação aberta a seu futuro.

${ }^{3}$ Ibid., 20. A Tradição fala do sábado como o fim das obras dos seis dias, afirmando que a criação está em função do sábado e, portanto do culto e da adoração a Deus. Porém, aqui o sábado é afirmado como o coração das leis de Israel, fim da primeira criação, mas para o cristianismo nasce um novo dia na ressurreição de Cristo, dando início a nova criação o oitavo dia (Catecismo da Igreja Católica, 101).

${ }^{4}$ Moltmann, J., Gott in der Schöpfung, 20; Beale, G.K. The new international Greek testament commentary: the Book of Revelation, 1155.

${ }^{5}$ Moltmann, J. Op.cit., 20.

${ }^{6}$ Ibid., 20. Essa perspectiva, está associada com a idéia da doutrina judaica da criação. Na visão moltmanianna, o sábado é a plenitude e a coroação da criação.

${ }^{7}$ Ibid., 21. O ano sabático aponta para o futuro messiânico: «Und dieses Sabbatjahr weist in der
} 
de Nazaré (Lc 4, 18s), afirmando que esta teve início com a proclamação messiânica e está articulada com sua ressurreição, vista como o início da nova criação ${ }^{8}$. Esta doutrina da criação situa-se no contexto de uma orientação multiplamente dialética e processual. Ao tomar da tradição teológica a sentença, «a graça não destrói, mas pressupõe e aperfeiçoa a natureza elabora-se a partir de um sentido novo de uma dialética tripartite: "A graça não aperfeiçoa, mas prepara a natureza para a glória eterna; a graça não é a perfeição da natureza, mas a preparação messiânica do mundo para o reino de Deus" .

O ponto de partida é que a graça de Deus deve ser vista, na ressurreição de Cristo, como o início da nova criação do mundo. Propõe-se associar natureza e graça com vistas à glória, que plenifica tanto a natureza quanto a graça, determinando, assim, a relação entre natureza e graça ${ }^{10}$. Portanto, o reino de Deus, pode ser chamado de fundamento interno da criação ${ }^{11}$. Partindo destes pressupostos, tem-se presente que na compreensão cristã, a criação é um ato trinitário, Afirmando que durante muito tempo, a tradição teológica acentuou somente a figura do Pai como Criador e Senhor da criação, e, considerando a doutrina cristológica da criação, Moltmann parte de uma ênfase no terceiro aspecto, a criação no Espírito ${ }^{12}$. Aqui se enfatiza que, de acordo com as tradições bíblicas, toda ação divina é pneumática em seu resultado ${ }^{13}$. O ponto de partida na Sagrada Escritura, para a compreensão da criação no Espírito, é o Sl 104, 29-30 em que o termo Ruah vem interligado à compreensão hebraica da sabedoria da criação (Prov. 8, 22-31) ${ }^{14}$. Neste contexto, a criação no Espírito é uma concepção teológica que melhor corresponde à doutrina ecológica da criação ${ }^{15}$.Uma doutrina ecológica da criação implica um novo modo

Geschichte wiederum über sich hinaus auf die Zukunft der messianischen Zeit. Jeder Sabbat ist eine heilige Vorwegnahme der Erlösung der Welt» (Ibid., 21).

${ }^{8}$ Ibid., 21; EDwards, D. Jesus the Wisdom of God, 77-78.

${ }^{9}$ Ibid., 21. (Schriften zur Theologie I, 169 ff; IV, 15, apud MOLTMANN, J., Op.cit., 21-22). Moltmann, não considera a segunda parte desta afirmação, pelo fato de que no seu ponto de vista, esta não diferencia entre graça e glória, entre história e nova criação, entre ser-pessoa-cristã e ser pessoa plena.

${ }^{10}$ Ibid.,22; Edwards, D. Op. cit., 84-87.

${ }^{11}$ Ibid., 22.

${ }^{12}$ Ibid.,23; Pannenberg, W. Systematic theology, II, 107-110.

${ }^{13}$ Ibid.,23; LADARIA, L Antropologia teologica, 65. O Espírito de Deus, não é só ativo na redenção humana, mas, já na criação (PANnenberg,W. Op.cit., III, 1).

${ }^{14}$ Ibid.24-25; ID; Christoph Pezel (1539-1604) und Calvinismus in Bremen, 25.

${ }^{15}$ Ibid., 26. Com esta concepção, Moltmann tem como objetivo resgatar a doutrina da criação da era da subjetividade e do domínio mecanicista do mundo e conduzi-la ao caminho do futuro de uma comunhão ecológica mundial. 
de pensar a imanência de Deus no mundo ${ }^{16}$. Postula-se a idéia que, para entender a imanência de Deus no mundo, precisa excluir o conceito causal e o pensamento causal com ele combinado. Propõe-se perceber Deus em relação com sua criação, como uma rede multifacetária de relações unilaterais, recíprocas e múltiplas . Partindo deste ponto de vista, associa-se a idéia do Deus Criador com o Deus que, ao criar o mundo, faz desse sua morada. Esta é a dialética: o Deus transcendente é o Deus imanente ${ }^{17}$.

Esta perspectiva vem interligada à idéia da doutrina rabínica e cabalística da Schechiná e a doutrina cristã trinitária ${ }^{18}$. Retomando o princípio de compenetração recíproca, acredita-se, que este movimento dialético reside na própria divindade ${ }^{19}$. A concepção de, "o Espírito na criação", tem como objetivo, entender criação e evolução como conceitos interligados ${ }^{20}$. Esta evolução da criação se explica mediante a perspectiva do reino de glória, e, portanto, como um conceito básico da auto-movimentação do Espírito divino da criação ${ }^{21}$.

\section{A doutrina ecológica da criação}

A doutrina da criação, nesta perspectiva, tem como objetivo, a abordagem e apresentação da situação crítica, na qual a fé, independentemente do lugar em que se encontra, e qual a sua contribuição ${ }^{22}$. Para isso, adota-se o modelo

\footnotetext{
${ }^{16}$ Ibid., 27; ID., Das Kommen Gottes, 287; EDwARDS, D. Op.cit., 153-154.

${ }^{17}$ Ibid., 28-29. A criação do mundo é possível reconhecer uma autodiferenciação e uma autoidentificação de Deus.

${ }^{18}$ Moltmann, J. Gott in der Schöpfung, 29. A Shechiná significa a presença de Deus, nas pessoas e sua morada entre elas, como uma separação que se dá no próprio Deus. Deus sai de si e se dá a seu povo. A doutrina cristã trinitária, apresenta Deus num transbordamento livre de seu amor. Deus sai de si mesmo, e produz a criação, uma realidade que existe como Ele existe, mas diferente Dele.

${ }^{19}$ Ibid. 29-30. A doutrina da Trindade formula diferenciações e unidades em Deus. A doutrina social da Trindade expressa as coabitações múltiplas e a eterna comunhão do Pai, do Filho e do Espírito Santo através do conceito da pericórese. Moltmann, contrapõe a K. Barth que, em sua teologia da soberania de Deus, refletiu a existência da sobreposição e subordinação, ordem e obediência, partindo para a apresentação das relações análogas na contraposição entre Deus e o mundo entre céu e terra. Na reflexão do modelo societário da Trindade pressupõe-se que as relações análogas a Deus espelham as coabitações originais recíprocas e a mútua compenetração da pericórese trinitária.

${ }^{20}$ Ibid., 32; HAFFner, P. Il mistero della creazione, 215-216.

${ }^{21}$ Ibid., 32; HaffNer, P. Op.cit., 176-177.

${ }^{22}$ Ibid., 34. Esta reflexão situa-se dentro de uma análise da civilização técnico-científica e pelo esgotamento da natureza através da intervenção humana, associando esta idéia à crise ecológica.
} 
da identidade e da relevância ${ }^{23}$. Tenta-se, aqui, articular a crise de dominação com a crise ecológica, à luz de uma filosofia natura ${ }^{24}$. Dentro desse processo, a teologia cristã é afetada pela crise ecológica do mundo, tanto quanto as ciências naturais, e as tecnologias ${ }^{25}$. Esta reflexão sugere a passagem de uma visão antropocêntrica do mundo a uma visão teocêntrica ${ }^{26}$. Para isso é necessário considerar as três fases em acordo com o respectivo relacionamento entre teologia e ciência natural ${ }^{27}$.

A primeira fase, a fusão das tradições bíblicas com a antiga concepção de mundo numa cosmologia religiosa. A segunda fase, a emancipação dos cientistas desta cosmologia. No momento atual, a teologia e a ciência se encontram em sua terceira fase ${ }^{28}$. Um quarto pensamento, vem da teologia bíblico-cristã, sobre o original julgamento do Criador: "Deus viu que tudo era bom" (Gn 1, 31). Contudo, a afirmação de São Paulo, sobre "a expectativa temerosa e a saudade da criatura a qual foi sujeita à vaidade, não voluntariamente, mas pela vontade

\footnotetext{
${ }^{23}$ Ibid., 35-36. A identidade da fé criacionista cristã tornou-se questionável diante da crise ecológica, e a relevância da fé criacionista precisa mostrar-se concepção e caminhos da crise ecológica do presente (ID., Erfahrungen theologischen Denkens, 290).

${ }^{24}$ Ibid., 36. Faz-se uma exaustiva análise das ciências naturais, o desenvolvimento tecnológico e suas implicações na sociedade e consequentemente na natureza. Esta visão está interligada a uma imagem de Deus. Dizia Francis Bacon: O objetivo do conhecimento científico das leis da natureza é o poder sobre a natureza e, com isso, o restabelecimento da imagem de Deus para a pessoa humana e do domínio do ser humano. R. Descartes declarou, em sua teoria da ciência, Discours de la méthode, que o objetivo das ciências naturais exatas é fazer do ser humano o "maître et possesseur de la nature" (Ibid., 41). Parte da concepção de que esta crise quebra uma concepção de mundo orientado para o progresso (Boff, L. Ecologia: grito da terra, grito dos pobres, 16-17). A crise ecológica tem sua raíz na perda da re-ligação e dos arquétipos que inserem o ser humano no universo. Tanto a tecnologia clássica, como a tecnologia moderna, são responsáveis pela degradação ecológica (Ibid., 101-103).

${ }^{25}$ Ibid., 41.

${ }^{26} \mathrm{Ibid}$., 45. Deste ponto de vista, a fé criacionista, precisa do reconhecimento meditativo para entender a criação. Reconhecer, nesta visão, significa não reconhecer para dominar, mas para participar. Aqui, resgata-se Agostinho que disse que nós reconhecemos à medida que amamos (Apud Moltmann, J. Op.cit.,46-47). Boff, L. Ecologia: grito da terra, grito dos pobres, Vozes Petrópolis, 1995. pp. 18-19.

${ }^{27}$ Ibid., 47; Queiruga, A. T. Recuperar a criação, 36-37.

${ }^{28}$ Ibid.,47-48. Na primeira fase, elementos panteístas da apoteose do cosmos, quanto elementos de diabolização do cosmos foram excluídos. Na segunda, a teologia da doutrina da criação desvinculou-se da cosmologia, reduzindo-se a uma fé criacionista pessoal. Dentro deste contexto, o autor acena para o conflito Galileu Galilei e outros, como C. Darwin e S. Freud. Na terceira, acredita-se na possibilidade de encontro, forçado pela crise ecológica. K. Barth afirmou que a ciência tem espaço livre para além daquilo que a teologia descreve como obra do Criador, e que a teologia precisa e deve se movimentar livremente, onde a ciência natural se encontra (BARTH, K. Kirchliche Dogmatik III/1 apud Moltmann, J. Op.cit., 50).
} 
daquele que a sujeitou, na esperança (Rm 8, 19-21)", serve melhor para a situação atual do mundo criado ${ }^{29}$. Esta idéia interliga-se à abertura de uma saudade direcionada para o futuro de glória ${ }^{30}$. Deste ponto de vista, a concepção, tanto da dialética da diferença sujeito e objeto, quanto da dialética histórica, abarcam somente a pessoa e não a natureza ${ }^{31}$.

Propõe-se uma nova orientação ecológica na relação da pessoa com sua própria natureza corporal, superando a metafísica moderna da subjetividade pela objetivação alienante da natureza, e chegando a uma metafísica não subjetivista $^{32}$. Outra direção para uma teoria ecológica objetiva é a proposta de uma naturalização da pessoa, que se reconhece produto da natureza ${ }^{33}$. Para a compreensão desta questão, faz-se necessário ligar a reflexão, aliança, criação e reino de Deus ${ }^{34}$, articulando a interpretação das histórias bíblicas da criação à luz do Evangelho de Cristo ${ }^{35}$. Esta idéia vem conectada à perspectiva escatológica da criação ${ }^{36}$. A criação vista como processo ganha sentido a partir do seu objetivo escatológico ${ }^{37}$. O termo re-conhecimento cristão de Deus é visto como reconhecimento em parábola, e cada re-conhecimento do mundo como criação; e reconhecimento metafórico deste mundo como parábola do mundo futuro ${ }^{38}$. Visto desta forma, o reconhecimento natural de Deus pertence à pneumatologia ${ }^{39}$. Esta idéia está interligada ao caráter messiânico, articulando o mundo presente em suas necessidades com a promessa do reino.

\footnotetext{
${ }^{29}$ MOLTMANN, J. Gott in der Schöpfung, 53; NoBILE, M. Teologia dell'Antico testamento, 202.

${ }^{30}$ Ibid. 53; HAfFner, P. Il mistero della creazione, Città del Vaticano 1999. 251-253.

${ }^{31}$ Ibid. 55-59.

${ }^{32}$ Ibid., 63. Isto implica em mudanças de paradigmas, num novo método capaz de articular pontos de vistas disjuntos do saber em um ciclo ativo (C. Cavalcanti, ed., Desenvolvimento e natureza, Cortez São Paulo, 1995.43-44).

${ }^{33}$ Ibid., 63; Esser, H.H. „Creazione“, 389-399.

${ }^{34}$ Ibid., 66; Becker, O. «Alleanza», 66-77; Nobile, M. Op. cit., 75.

${ }^{35}$ Ibid., 66; BEALE, G.K. The new international Greek testament commentary, 173-174.

${ }^{36}$ Ibid.,66: «Das aber bedeutet, dab Israel nicht nur ein protologisches, sondern zugleich damit auch ein eschatologisches Verständnis der Schöpfung entwickelt hat». O autor diz que as diferentes tradições bíblicas falam da criação de Deus em vista do princípio dos tempos, do tempo histórico e do tempo escatológico.

${ }^{37}$ Ibid., 67; Mundle, W. „Venire“, in Dizionario dei concetti biblici del nuovo testamento, EDB, Bologna, 2000. pp. 1935-1942.

${ }^{38}$ Ibid., $71 .$.

${ }^{39}$ Ibid., 72; A doutrina da criação de Moltmann, não é somente uma doutrina sobre a origem do mundo, mas, sobre as relações do Deus Criador com sua criação e o ser humano como parte do mundo criado. $\mathrm{O}$ acento do envolvimento de Deus na criação era inicialmente cristológico, tornando-se pneumatológico (BAUCKHAM, R. The theology of J. Moltmann., 183-186).
} 
Aqui, teologia natural e teologia da revelação não são separadas, embora mantenham diferentes situações, e condições históricas ${ }^{40}$. Deste ponto de vista, teologia da revelação é considerada teologia messiânica, sob o pressuposto do Messias e o começo do tempo messiânico ${ }^{41}$

Paulo apresentou a luz messiânica como re-conhecimento do mundo, como criação (Rm 8, 19s). Este re-conhecimento deve ser ponto de partida para refletir sobre a criação no momento atual ${ }^{42}$. Nesse contexto, propõe-se uma compreensão do mundo como parábola, onde as parábolas neotestamentárias mostram a presença oculta do futuro do reino vindouro, e estas são interpretadas escatologicamente como parábolas histórica do mundo futuro e não ontologicamente como parábolas terrenas da glória celestial ${ }^{43}$.

A parábola entendida como presença oculta de um futuro qualitativamente novo e salvífico, transforma-se em promessa. Contudo, não se pode ignorar que o significado do reino de Deus ultrapassa o horizonte das experiências do mundo e dos próprios conceitos ${ }^{44}$. Esta visão postula que o reino de Deus representa a meta escatológica, não só da história humana, mas também do todo cosmos material ${ }^{45}$. Desse modo, a teologia do caminho (Theologia viatorum) é completada e superada pela teologia da Pátria (Theologia Patriae $)^{46}$. Isso conduz a um re-conhecimento messiânico do mundo mediante a consciência de que o testemunho neotestamentário da criação consiste no kerygma da ressurreição e na experiência do Espírito Santo, na força da nova

\footnotetext{
${ }^{40} \mathrm{Ibid} ., 72$. A teologia natural é uma teologia sob as condições do reino natural, (regnum naturae), enquanto que a teologia revelada é aquela teologia do reino da graça. E a teologia da glória, seria a teologia do reino da glória.

${ }^{41}$ Ibid., 73; Rengstorf, K.H. «Gesù Cristo», 747-760.

${ }^{42}$ Ibid., 73; BAUскнам, R. God will be all in all: the eschatology of Moltmann, J., 279.

${ }^{43}$ Ibid., 74-75. Moltmann resgata K. Barth, que elaborou sua reflexão do mundo como parábola, assumindo apenas o objetivo, não o método e a pretensão moderna da teologia natural; mas, assumiu a metáfora do ator, assumindo a metáfora do mundo de Calvino, o mundo como teatro da glória de Deus (theatrum gloriae Dei) (ID.,Die ersten Freigelassenen der Schöpfung, 25). Barth acentuou a diferença fortemente, de forma que, por um lado só concebe o mundo criado, a criação no princípio da sua manutenção, mas não a história da criação continuada e contingente, já que Barth festeja o «ser revelado da conciliação» já como sendo o «triunfo da glória» ("Triumph der Herrlichkeit feiert"). Porém, em K. Barth, o pensamento da criação como esboço do reino de Deus, quase não aparece.

${ }^{44}$ Ibid., 73; Klapert, B. "Regno", 1513-1527.

${ }^{45}$ Ibid., 76-77. A idéia é que uma promessa aponta para sua realização e antecipa o futuro que ainda há de vir. No cumprimento, a promessa é superada. Aqui, articula-se a doutrina teológica dos vestígios de Deus, que vê na criação, rastros, vestígios de Deus, os quais são vestígios do reino prometido.

${ }^{46}$ Ibid., 78; KLAPERT, B. Op. cit., 1513-1523.
} 
criação ${ }^{47}$. Portanto, acontece tanto na cristologia, quanto na pneumatologia escatológicas uma fundamental reinterpretação do criar divino ${ }^{48}$.

Paulo, em $(\mathrm{Rm} 4,17)$ ao falar de Abraão como pai da fé, relaciona a fé à ressurreição dos mortos e a criação ${ }^{49}$. Em Paulo, a iluminação da fé é compreendida através do re-conhecimento de Cristo em perspectiva com a criação da luz no início, relacionada à luz da nova criação $(2 \text { Cor } 4,6)^{50}$. Tendo presentes estes aspectos, parte-se de uma análise da sequencia da criação conforme os relatos veterotestamentários da criação ${ }^{51}$. Ao resgatar da tradição sacerdotal o termo "bará" como aquele que designa o criar divino, qualifica a criação como algo essencialmente novo ${ }^{52}$. Entretanto, na doutrina da criação da teologia processual, defende-se a idéia de uma criação a partir do caos. Mas esta visão também pode ser limitada. Daí, a importância de se interpretar a nova criação no sentido de uma nova humanidade ${ }^{53}$.

A reflexão sobre a criação em $\mathrm{K}$. Barth tem, como ponto de partida, a doutrina reformada dos decretos, porém, ele a corrigiu na sua doutrina cristológica da eleição, uma vez que não assumiu a ordem reformada dos decretos, mas declarou a aliança e não a glória como sendo o fundamento interior da criação ${ }^{54}$. A doutrina da emanação, na forma em que foi defendida por Paul Tillich, é aqui assumida como aquela que contém, em si, elementos de verdade imprescindíveis para a compreensão total da criação ${ }^{55}$. O objetivo é assegurar a identidade da vida divina e do criar divino ${ }^{56}$. Ao retomar a idéia da criação a partir do nada, essa idéia vem associada à doutrina judaico-cabalística da auto-comunicação de Deus, porém, na perspectiva messiânica da fé no Filho crucificado de Deus ${ }^{57}$.

${ }^{47}$ Ibid., 78-79.

${ }^{48}$ Ibid., 78-79.

${ }^{49}$ Ibid., 78-79.

${ }^{50}$ Ibid., 78-79.

${ }^{51}$ Ibid., 85; Nobile, M. Teologia dell'Antico testamento, 71-72.

${ }^{52}$ Ibid., 86.

${ }^{53}$ Ibid., 92.

${ }^{54}$ BARTh, K.. Kirchliche Dogamatik II/2,181; ähnlich IV/ 2, 386; II/2,9 (MOLTMANN, J., Op.cit. 92-98).

${ }^{55}$ Vida divina e criar divino são uma só coisa. A criação não é, portanto, um evento de Deus, mas idêntica com sua vida. Desta forma, criação não é nem causalidade nem necessidade, mas o destino de Deus. Partindo deste pressuposto, não se pode falar de um início temporal, mas, de relações entre Deus e o mundo (Tillich, P. Systematische Theologie I, 290; Moltmann, J., Op.cit., 96).

${ }^{56}$ Ibid., 96; Barteles, K.H.“'Uno, una volta unico", in Dizionario dei concetti biblici del nuovo testamento, Bologna 2000. pp. 1903-1909.

${ }^{57}$ Ibid., 96. 
Desde Agostinho, a teologia cristã denomina a obra criadora de Deus como um agir de Deus para fora (operatio Dei ad extra, opus trinitatis ad extra, actio Dei externa). Diferenciando de um agir de Deus para dentro, que se desenrola nas relações intratrinitárias de Deus ${ }^{58}$. Este «extra Deum» é, nesta reflexão, interligado ao postulado de uma auto-restrição de Deus, que precede a sua criação, podendo ser combinado, sem contradições, com a divindade de Deus ${ }^{59}$.

Através de sua contração, Deus dá espaço à criação ${ }^{60}$. A diferença entre Criador e criatura é assegurada na verdade de que Deus é tudo em tudo. Este movimento da auto-contração de Deus para a descontração escatológica, é para ser compreendido na dialética, processo da antiga criação com o processo da nova criação ${ }^{61}$. Assim sendo, escatologia é a fé da criação orientada para o futuro. A fé no Deus que criou do nada é a fé no Deus que ressuscita os $\operatorname{mortos}^{62}$. Esta reflexão tem por objetivo, e aqui chega a seu intento, o desdobrar do monoteísmo veterotestamentário, trinitariamente ${ }^{63}$. Para isto, articula-se a idéia da redenção da criação em Cristo com a fundamentação protológica da criação através de Cristo, o que se pode perceber na base das afirmações neotestamentárias sobre o Cristo como mediador da criação ${ }^{64}$.

\section{Espírito Santo na criação}

Do ponto de vista desta reflexão, os testemunhos neotestamentários, o Espírito Santo como criador e sua força na experiência da comunidade, fazem parte da experiência da graça escatológica (2Cor 1, 22; 5, 5). Esta experiência

\footnotetext{
${ }^{58}$ Ibid., 96; MONDIN, B. "Creazione”, in Dizionario dei concetti biblici del nuovo testamento, Bologna 2000. pp. 1903-1909.

165-172; IRINEU DE Lião, Liv. I, 22, 1, 97.

${ }^{59}$ MOLTMANN, J., Gott in der Schöpfung, 96-100. Para o infinito, o eterno, criar algo fora do seu próprio ser, o eterno Deus deve ter dado lugar para o finito em si mesmo. Esta idéia foi desenvolvida por Isaak Luria em sua doutrina do Zimzum que significa, concentração e contração e quer dizer, retirar-se em si mesmo. O que se interliga à antiga doutrina da Schechiná (SCHOLEM, G. Schöpfung aus Nicht und Selbstverschränkung Gottes, 124, apud MOLTMANN, J., Op.cit., 98-99.

${ }^{60}$ Ibid., 100-101.

${ }^{61}$ Ibid., 101-103; BeAle, G.K. The Book of revelation, 1109, afirma que João (Ap 21, 1), teve a visão do novo céu e a nova terra, mas a visão, (Ap 21, 2; 9-22: 5), é só de um paraíso cidade-templo. É possível que primeiro João tenha visto o todo do céu e da terra, e subsequentemente viu só a cidade-templo o que é uma parte do novo cosmos.

${ }^{62}$ Ibid., 103-105; Ladaria, L. Antropologia teologica, 89.

${ }^{63}$ Ibid., 106; Brown, R. The gospel accoding to John I-XII: a new translation with introduction and commentary, 25.

${ }^{64}$ Ibid., 106-107.
} 
do Espírito é a experiência da Shechiná (1Cor 6, 13-20). Porém, isto é visto em perspectiva trinitária. A presença e a ação do Espírito são o objetivo escatológico da criação e da reconciliação ${ }^{65}$. O Espírito, na criação, aponta para o Pai e para o Filho. Portanto, o termo trinitário da criação, liga transcendência de Deus no mundo com a sua imanência no mundo ${ }^{66}$. Na concepção trinitária da criação, são integrados os momentos de verdade do monoteísmo e do panteísmo ${ }^{67}$.

Na concepção trinitária da criação, a idéia do Cristo cósmico se relaciona com a idéia do Espírito cósmico presente como força criadora (Jo 3, 5; 2Cor 5, 17) e a experiência de comunhão do Espírito nos limites, sociais e religiosos e ao futuro da nova criação ${ }^{68}$. Sendo o Espírito presença imanente de Deus no mundo, então é possível falar de uma kénosis do Espírito. Aqui se parte do pressuposto de uma ligação entre encarnação do logos e habitação do Espírito ${ }^{69}$. $\mathrm{Na}$ tentativa de evitar um panteísmo do Espírito no mundo, toma-se a idéia de H. Heine que, rejeitando o panteísmo, afirmou que Deus está em tudo, mas tudo não é Deus, apontando, desta forma, para a diferença entre panteísmo e pan-en-teísmo ${ }^{70}$. Contudo, o panenteísmo diferenciado não consegue conectar a imanência de Deus no mundo com a sua transcendência do mundo; o que é possível à doutrina trinitária da criação no Espírito e do Espírito criador que habita na criação ${ }^{71}$.

\section{Tempo e eternidade}

Um outro elemento importante diz respeito à relação tempo e eternidade e à vinda de Deus ${ }^{72}$. Agostinho aprofundou a reflexão sobre o tempo da criação, dedicando todo capítulo 11 de suas Confissões, sobre esta questão: "Quid est tempus" "73. K. Barth, afirmou que o tempo não existiu antes da

${ }^{65}$ Ibid., 107. (Ef 1, 14; Jl 3, 1 ; Ap 21, 3).

${ }^{66}$ Ibid., 107-109.

${ }^{67}$ Ibid., 109.

${ }^{68}$ Ibid., 110-111. Articula-se a reflexão sobre o Espírito Santo como princípio de criatividade, ao princípio holístico, com o princípio de individualização e da formação de determinados esboços de matéria e de vida, acrescentando o princípio de intencionalidade como algo inerente a todos os sistemas de vida e matéria. Todavia, seu objetivo é a aplicação do termo pericórese trinitária na criação.

${ }^{69}$ Ibid. 113, "Kenosis des Geistes » (Hegel, Phänomenologie des Geistes, Hamburg 1852.561; ID., Vorlesungen über die Philosophie der Religion, I, 221).

${ }^{70}$ Ibid., 115.

${ }^{71}$ Ibid, 115; IOANNES PAULUS pp. II, Litt. enc. Dominum et vivificantem, n. 12.

${ }^{72}$ Ibid., 116-131.

${ }^{73}$ Ibid., 124-125. 
criação. Antes da criação, somente a eternidade de Deus, a qual se revela no ato da criação como sua temporal disposição para o tempo ${ }^{74}$. Barth, chamou o tempo, em oposição à eternidade, dessa disposição simultânea do presente, passado e futuro, esse rio da existência do passado, passando pelo presente em direção ao futuro ${ }^{75}$. Porém, essa não é a única possibilidade de qualificar o tempo através daquilo que nele acontece ${ }^{76}$. As tradições bíblicas falam da experiência da vida do tempo na história de Deus com o mundo, determinadas por promessas, aliança, salvação, redenção e outros feitos de Deus ${ }^{77}$.

Um ponto importante para a compreensão do tempo, é a idéia de que Israel, conheceu primordialmente a compreensão do tempo como kairós (Ecl 3, 1-8). E por isso Israel falava de tempo no plural, e não considerava o acontecimento como algo homogêneo ${ }^{78}$. Num segundo momento, Israel desenvolve uma concepção de tempo baseada nas promessas ${ }^{79}$. O reconhecimento das experiências em acontecimentos únicos e históricos levou Israel a conquistar a concepção de uma sequencia sucessiva de história ${ }^{80}$. Com a palavra chave de, G. von Rad , "escatologização do pensar histórico" se pode descrever a experiência profética do tempo ${ }^{81}$. No pano de fundo transcendente da fidelidade de Deus, os profetas descobrem aquelas analogias no que passou, com as quais eles anunciam, então, o novo criar de Deus. O novo criar de Deus trará o novo êxodo e a nova aliança, a nova posse da terra, a nova Jerusalém ${ }^{82}$. A literatura apocalíptica mostra que esta experiência presente de rompimento de todas as pontes na história passada de Deus pode aumentar a diferença entre passado e futuro em dimensões cósmicas ${ }^{83}$. A total compreensão messiânica do tempo no Novo Testamento pressupõe a doutrina

\footnotetext{
${ }^{74}$ Barth, K. Kirchliche Dogmatik III/1, 75, apud MOLTMANN, J. Op.cit., 127.

${ }^{75}$ Essa direção do tempo apontada por K. Barth se contrapõe a concepção de tempo em Agostinho apud MOLTMANN, J. Op.cit. 127).

${ }^{76}$ MOLTMANN, J., Gott in der Schöpfung, 129; NobILE, M. "Tempo", in Dizionario dei concetti biblici del nuovo testamento, Bologna 2000 235-236.

${ }^{77}$ Ibid., 129.

${ }^{78}$ Ibid., 129.

${ }^{79}$ Ibid., 130; MACKENZIE, J.L. „Promessa“ 747-748.

${ }^{80}$ Ibid., 130.

${ }^{81}$ Ibid., 131; LAdaria L., "Escatologia", in Dicionário de teologia fundamental, Santuário Aparecida, 1994. pp. 260-262.

${ }^{82}$ Ibid., 131. O velho e o novo agir de Deus não estão no mesmo tempo.

${ }^{83}$ Ibid., 132, ID; Umkehr Zukunft, 30-50; HAHN, H. "Tempo", in Dizionario dei concetti biblici del nuovo testamento, Bologna 20001808-1830.
} 
apocalíptica dos tempos ${ }^{84}$. E essa deve apontar para a concepção de que a criação acena para o reino eterno ${ }^{85}$.

O uso do conceito de História, vem diferenciado entre o conceito de história dentro dela mesma, para integrá-lo dentro do conceito maior da natureza: primeiro mediante uma modalização dos tempos: passado, presente e futuro; segundo através da limitação da história, através da sincronização dos tempos humanos com o tempo natural do ecossistema - terra. Em ambas perspectivas, trata-se de uma concepção pericorética dos tempos ${ }^{86}$. Com relação à concepção de futuro, com base em Ap 1, 4, entende-se futuro no lugar de futurum ${ }^{87}$. Porém, esta idéia está interligada à concepção de futuro-advento e unidas, correspondem à antecipação do que está para $\operatorname{vir}^{88}$. Mas, o objetivo é sempre pensar e repensar a história dentro da comunhão da humanidade articulada com a crise ecológica, os limites éticos, na tentativa de superar um antropocentrismo, substituído por um novo teocentrismo cosmológico, em que o centro da criação é o sábado, como coroa da história ${ }^{89}$. Nesta idéia, a categoria de espaço é fundamental enquanto conceito ecológico o que corresponde ao conceito de kairós do tempo. Nem tempo e nem espaço são homogêneos ${ }^{90}$. Esta reflexão é influenciada pela concepção do espaço vazio.

\section{O Ser humano na complexidade da criação}

Trata-se da doutrina do "zimzum" de Deus: Deus ("creaturus mundos contraxit praesentiam suam") ${ }^{91}$. Postula-se a idéia de que, após Deus, com vistas à criação do mundo, ter realizado a auto-contração, criou recipientes ${ }^{92}$. O mundo criado não existe no espaço absoluto da existência de Deus, mas no espaço arrumado pelo próprio Deus através da criação ${ }^{93}$. Aqui, o relacionamento do Criador com a sua criação encontra sua analogia na relação céu e terra.

\footnotetext{
${ }^{84}$ Ibid., 132-134.

${ }^{85}$ Ibid., 134-135; GANOCZY, A. "Criação", in Dicionário de conceitos fundamentais de teologia, Paulus, 1993. pp. 135-139.

${ }^{86}$ Ibid., 136.

${ }^{87}$ Ibid., 134-135; BEALE, G. K. The new international Greek testament commentary, 186-187.

${ }^{88}$ Ibid., 134-135; MundLE, W. «Venire», 1935-1941.

${ }^{89}$ Ibid., 149-150; ID., Das Kommen Gottes, 287-294; ID; Mensch. Christliche Anthropologie in den Konflikten der Gegenwart, 152.

${ }^{90}$ Ibid., 151-153; Torrance, T, F, Space, time and incarnation, 11, 22.

${ }^{91}$ Ibid., 166; PAnnenberg, W. Systematic theology, 89.

${ }^{92}$ Ibid., 162; Torrance, T.F, Space, time and Incarnation, 59-63.

${ }^{93}$ Ibid., 162-166.
} 
Porém, não é uma concepção dualista, mas assume um caráter de comunhão ${ }^{94}$. As categorias céu e terra são entendidas como espaços criados na história trinitária de Deus, somente entendidas na plenitude de suas relações ${ }^{95}$. Esta concepção relaciona-se à idéia de reino no sentido de que o Deus Criador se decide a partir da plenitude de suas possibilidades em favor das possibilidades criadoras e contra as possibilidades destruidoras ${ }^{96}$. Ao analisar-se criticamente alguns aspectos teológicos das tradições luterana e católica, acena-se para os limites da crítica moderna sobre a concepção de céu e terra, na tentativa de elaborar uma reflexão sobre o reino da glória como a morada de Deus em toda sua criação ${ }^{97}$. Esta concepção, vem associada à ressurreição de Jesus numa perspectiva escatológica ${ }^{98}$. Ao refletir sobre a evolução da criação, rejeita-se a cosmovisão antropológica desta, e faz-se um deslocamento da pessoa humana do centro do cosmos, concedendo esse espaço ao sábado ${ }^{99}$.

O termo evolução é refletido de forma distinta entre o sentido restrito de evolução, e evolução enquanto descreve «creatio continua», o que quer dizer, que a criação não está pronta. Esta idéia inter-liga-se à uma concepção da fé criacionista bíblica em perspectiva messiânica ${ }^{100}$. O processo da evolução de sistemas de matéria e de vida não é uma corrente unilinear, mas assemelha-se a uma rede de partículas elementares e de estruturas, que crescem e se expandem nos espaços possíveis do futuro ${ }^{101}$. Há uma articulação entre possibilidades e probabilidade ${ }^{102}$.

O universo é entendido através do pressuposto de um contexto transcendente com o qual está em comunicação e um futuro transcendente para dentro do qual ele se desenvolve ${ }^{103}$. O cosmos evolutivo é compreendido como sistema irreversível, comunicativo e aberto para o futuro ${ }^{104}$. A transcendência

${ }^{94}$ Ibid., 171; Bietenhad, H. „Cielo“, in Dizionario dei concetti biblici del nuovo testamento, Bologna 2000. pp. 275-286.

${ }^{95}$ MOLTMANN, J., Gott in der Schöpfung, 171.

${ }^{96}$ Ibid., 167-189; BARTH, K. Kirchliche Dogmatik III/2 Tillich, P. Systematische Theologie, I, 248.

${ }^{97}$ Ibid., Gott in der Schöpfung, 191; ID., Das Kommen Gottes, 327.

${ }^{98}$ Ibid., 191-192.

${ }^{99}$ Ibid., 193-194. O ser humano é o ser mais elevado, mas não é a coroa da criação, mas membro da comunidade da criação em relação. (Gn 1,20.30; 2, 19; 1, 22; 26;) Céus e terra serão recriados (Ap 21, 5). Moltmann, faz aqui, uma exaustiva análise da teoria evolucionista moderna e científica, seus limites e contribuições.

${ }^{100}$ Ibid., 204.

${ }^{101}$ Ibid., 210.

${ }^{102}$ Ibid., 210-211; DAviEs, P. L 'universo che fugge, 223-224.

${ }^{103}$ Ibid., 210-212; (DAvies, P. Op. cit. 224-225).

${ }^{104}$ Ibid., $210-212$. 
do mundo para Deus depende da imanência de Deus no mundo. O mundo como um sistema aberto, participatório e antecipatório ${ }^{105}$. Daí que, ao falar de criação continuada, diferencia-se entre o criar original de Deus e seu criar na história; o criar no início é sem precedentes, o criar histórico pressupõe a criação em perspectiva da nova criação ${ }^{106}$. A doutrina trinitária da criação leva a uma compreensão da natureza de forma pneumatológica na qual é presente o Espírito criador ${ }^{107}$.

O ser humano, como imagem de Deus, é compreendido na perspectiva histórica: a) a determinação original das pessoas: imagem de Deus ("imago Dei”), b) A vocação messiânica das pessoas (“imago Christi”), c) A glorificação escatológica das pessoas: o homem a glória de Deus ("gloria Dei est homo") ${ }^{108}$. O conceito de imagem de Deus é, antes, um conceito teológico, depois antropológico. Daí a relação de Deus para com a pessoa e, a partir desta, a relação da pessoa para com Deus ${ }^{109}$. Portanto, Deus se reflete na sua imagem como num espelho, tornando as pessoas a aparição de sua glória ${ }^{110}$. A semelhança do ser humano com Deus associa-se a Jesus Cristo, Imagem perfeita do Pai, torna as pessoas aquilo para o qual foram determinadas ${ }^{111}$. Trata-se de refletir a glorificação escatológica das pessoas; glória de Deus articulando a idéia da criação criada para o sábado e o homem para a glória de Deus ${ }^{112}$, porém, sempre considerando a dialética: imagem de Deus e simultaneamente pecador ${ }^{113}$. O objetivo é partir de uma doutrina decisivamente social da semelhança de Deus nas pessoas em uma teologia da Trindade aberta, diferenciada. Assim sendo, associa-se a criação do Pai salva e completa, das pessoas através do Espírito, na imagem do Filho ${ }^{114}$. O ser imagem de Deus, relaciona-se à idéia da corporalidade como fim de todas as obras da criação de Deus; como uma alternativa ao dualismo antropológico ${ }^{115}$. Esta corporalidade compreendida como a nova corporalidade transfigurada, realizada no

\footnotetext{
${ }^{105}$ Ibid., 213; QUEIRUGA, A.T. Recuperar a Criação, 104;

${ }^{106}$ Ibid., 215.

${ }^{107}$ Ibid., 219-220; PANNENBERG, W. Systematic theology, II, 109-110.

${ }^{108}$ Ibid., 222-223.

${ }^{109}$ Ibid., 226.

110 Ibid., 226.

${ }^{111}$ Ibid., 226-233; AGOSTINHO, Enarrationes in psalmos, 9/3, 1015.

${ }^{112}$ Ibid., 233; ID; Zukunft der Schöpfung, 157-179. ID., Gott im Projekt der modernen Welt, 107-108.

${ }^{113}$ Ibid., 235-242.

${ }^{114}$ Ibid., 246-247; ID., Erfahrungen theologischen Denkens, 275.

${ }^{115}$ Ibid., 248-249; ID; "A unidade convidativa do Deus uno e trino", 54-63; CrouzEL, H. "Imagem”, in Dizionario dei concetti biblici del nuovo testamento, Bologna 20001082-1086.
} 
Espírito $^{116}$, vem interligada à forma pericorética de corpo e alma numa interligação da comunhão trinitária (Jo 17,21).

\section{A doutrina do sábado}

O ponto de partida é a unidade intratrinitária do amor divino, e consequentemente, sua relação recíproca com a criação ${ }^{117}$. Um ponto de importância fundamental nesta reflexão, o qual se tem acenado, é a doutrina do sábado. $\mathrm{O}$ sábado, articulado como o dia do descanso de Deus e de sua criação ${ }^{118}$. O sábado é entendido como a auto-revelação de Deus, o dia do Senhor. No sábado, um tempo, é abençoado mediante o descanso de Deus, no qual todas as criaturas descansam ${ }^{119}$. A santidade do sábado está ligada à liberdade. O descanso sabático pode ser compreendido como a doutrina da justificação judaica; e a doutrina cristã da justificação pode ser considerada o descanso sabático cristão ${ }^{120}$.

A idéia do sábado como conclusão da criação, e como revelação da existência repousante de Deus em sua criação, acena para além do sábado; aponta para um futuro no qual criação e revelação de Deus se tornam redenção entendida como o sábado eterno e nova criação ${ }^{121}$. Porém, o ano sabático (Lv 25, 1-7), e o ano jubilar ( $\operatorname{Lv} 25,8-55)$ e a visão profética do ano messiânico (Is 61, 1-11), estão interligados e apontam para além do tempo histórico, isto é, para o tempo messiânico. No final dos tempos, o sábado se transformará, numa festa sem fim ${ }^{122}$. Propõe-se, aqui, interligar o sábado ao Domingo, ao dia da ressurreição de Cristo, o dia do Senhor, o que antecipa não só o descanso sabático do final do tempo, mas o início da nova criação ${ }^{123}$. O sábado permite participar do descanso de Deus, a festa da ressurreição permite participar da força na re-criação do mundo ${ }^{124}$. Este dia é pensado como o primeiro dia da semana ${ }^{125}$.

\footnotetext{
${ }^{116}$ Ibid, 250; CROUZEL, H. Op. cit., 1082-1086.

${ }^{117}$ Ibid., 261; 278.

${ }^{118}$ Ibid., 279-281; MAYER, R. "Feste, Festa di Pasqua", in Dizionario dei concetti biblici del nuovo testamento, Bologna 2000 631-640.

${ }^{119}$ Ibid., 282-284; STUDER, B. "Creación", in Diccionario patristico y de la antigüedad cristiana, $1^{\circ}$ vol. Salamanca 1998. 508-511.

${ }^{120}$ Ibid., 28; RORDORF, W. "Sabado", in Diccionario patristico y de la antigüedad cristiana, $2^{\circ}$ vol. Salamanca 1998. pp. 1919-1920.

${ }^{121}$ Ibid., 290.

122 Ibid., 291-292.

${ }^{123}$ Ibid., 295-297.

${ }^{124}$ Ibid., 297; MAYER, R. "Feste, Festa di pasqua", in Dizionario dei concetti biblici del nuovo testamento, Bologna 2000. pp. 631-640.

${ }^{125}$ Ibid., 298; MAYer, R. "Feste, Festa di pasqua", 631-640.
} 
A idéia de festa do dia da nova criação pressupõe o dia de descanso ecológico da criação original na perspectiva da conclusão da nova criação ${ }^{126}$. Essa perspectiva assume um caráter festivo na ressurreição de Jesus como festa escatológica da re-criação do mundo, relacionando o sábado israelita, orientando-se numa esperança messiânica, onde o reino de Deus é celebrado na simbologia de um matrimônio (Mt 22, 2s; 25, 1s) e o Cristo vindouro será recebido como noivo e a Igreja o receberá na qualidade de noiva ${ }^{127}$. Esta simbologia está interligada às metáforas da Igreja antiga, do mundo como dança, e esta como legitimidade da expressão de liberdade e redenção do corpo. O desenvolvimento da categoria dança, acentua a importância da eterna pericórese trinitária como uma dança eterna interconexa com a dança cósmica $^{128}$, transformando-se na dança messiânica da vida eterna ${ }^{129}$.

Do ponto de vista de Moltmann, estes símbolos, assumidos em perspectiva messiânica, superam toda e qualquer visão patriarcal ou matriarcal da vida. Simbolizada no reino da criança, a vocação messiânica do Espírito anula a supremacia religiosa, tanto do homem quanto da mulher. No cristianismo, isso se dá através do batismo, símbolo da vocação escatológica e do lacre do reino messiânico, baseado no princípio de igualdade, que homem e mulher recebem na comunhão com Cristo, o novo e escatológico direito de herança, relacionado com uma nova visão ecológica e universal, orientado para o futuro ${ }^{130}$.

\section{Conclusão}

Sem dúvida, Jürgen Moltmann, ao sistematizar a história da criação e a crise ecológica articulandas à vida humana, torna surpreendentemente claro que todas as coisas no universo são interligadas. Há uma relação interior entre o que acontece nas estrelas e o que acontece na evolução da vida na terra. Dessa forma, o ser humano, enquanto imagem e semelhança de Deus pode contribuir com o resgate da vida do planeta: em primeiro lugar iniciando um processo de conversão e, a partir desse redescobrindo o Deus trinitário em suas relações de comunhão e unidade. Em segundo lugar, conhecer a natureza como criação de

\footnotetext{
${ }^{126}$ Ibid., 298.

${ }^{127}$ Ibid., 305- 306.

${ }^{128}$ MOLTMANN, J., Gott in der Schöpfung, 309; PröPer, T. „Liberdade“ in Diccionario patristico $y$ de la antigüedad cristiana, $1^{\circ}$ vol. Salamanca 1998. pp. 464-478.

${ }^{129}$ Ibid., 309.

${ }^{130}$ Ibid., 319-320.
} 
Deus e perceber nessa a presença do Espírito divino, e, a partir desse conhecimento aprender a se relacionar com o meio ambiente. Para isso, J. Moltmann sugere o respeito ao sábado do universo como princípio de equilíbrio entre a humanidade e a natureza. A ética sabática proposta por Moltmann é substancialmente bíblica que reconhece no sábado a lei do criado: o criador completa a criação do mundo, mediante a celebração do sábado do universo. Deus em seu dinamismo trinitário bendiz sua obra mediante sua presença. O sétimo dia é a festa da criação. Esta é a verdadeira política ambiental que dá significado a questão ecológica. Portanto, a política ecológica de J. Moltmann é a tentativa admirável de responder em perspectiva teológica aos grandes problemas que se propagam nas dimensões: social, política e ecológica.

\section{Referências Bibliográficas}

AALEN, S., "Gloria", in in Dizionario dei concetti biblici del nuovo testamento, EDB, Bologna, 2000.

Agostinho, Comentário aos salmos. São Paulo: Paulus, 1997.

BARTELES, K. H.,.'Uno, una volta unico“, in Dizionario dei concetti biblici del nuovo testamento, Bologna 2000.

BARTH, K., History and eschatology, New York 1962.

, Die Kirche Dogmatik, II/2 e III/3, Edinburgh 1955.

BAUCKHAM, R.., "L'escatologia della croce di Moltmann", in Dicussion über J. Moltmanns Buch "Der gekreuzgte Gott”, München 1979. ed. italiana, Dibattito su Il Dio crocifisso di J. Moltmann, Brescia 1982. , The theology of J. Moltmann, Edinburg 1995.

, God will be all in all: the eschatology of J. Moltmann, Edinburg 1999.

BEALE, G. K., The international Greek Testament commentary: the book of Revelation, Cambridge 1999.

BECKER, K. H., O. "Alleanza” in in Dizionario dei concetti biblici del nuovo testamento, EDB, Bologna, 2000.

BIETENHAD, K., "Cielo", in Dizionario dei concetti biblici del nuovo testamento, Bologna 2000.

BOFF, L., Ecologia: grito da terra, grito dos pobres, Vozes Petrópolis, 1995

BROWN, R., The gospel accoding to John I-XII: a new translation with introduction and commentary.

BUSATO, S., Il cammino della speranza: uno sguardo prospettico sull'itinerario teologico-antropologico di J. Moltmann, Verona 2000. 
CAVALCANTI, C., (org.), Desenvolvimento e natureza, Cortez São Paulo, 1995.

CROUZEL, H., "Imagem", in Dizionario dei concetti biblici del nuovo testamento, Bologna, 2000.

DAVIES, P., L'universo che fugge: la storia dell'universo dal big bang alla morte termica, Mandadori, Milano, 1979.

EDWARDS, D., Jesus the Wisdom of God, ST Pauls Australian 1995.

ESSER, H.H., "Creazione", in Dizionario dei concetti biblici del nuovo testamento (389-399. 244).

GANOCZY, A. "Criação", in Dicionário de conceitos fundamentais de teologia. São Paulo: Paulus, 1993.

HAHN, H., "Tempo", in Dizionario dei concetti biblici del nuovo testamento, Bologna, 2000

HEGEL, G.F., Phänomenologie des Geistes, Hamburg ,1852.

Ioannes, Paulus pp. II, Litt. enc. Dominum et vivificantem, Roma, 1986.

Irineu de Lião, Liv. I, 22, 1, 97.

KLAPERT, B., "Regno", in Dizionario dei concetti biblici del nuovo testamento, Bologna 2000.

LADARIA, L., Antropologia teologica, Piemme, Casale Monferrato - Via del Carminne, 1998.

MAYER, R., "Feste, Festa di Pasqua", in Dizionario dei concetti biblici del nuovo testamento, Bologna 2000.

METZ, J.B., Christliche Anthropozentrik, über die Denkform des Thomas von Aquinn,München, 1962.

MOLTMANN, J., Gott in der Schöpfung, München, 1993.

, Das Kommen Gottes, München, 1995.

, Christoph Pezel (1539-1604) und der Calvinismus in Bremen, Verlag Einkehr, Bremen 1958.

, Die ersten Freigelassenen der Schöpfung,

, Theologie der Hoffnung: untersuchungen zur Begründung und zur den Konsequenzen einer Christlichen Eschatologie, München, 1964. , Anfänge der dialektischen Theologie, hrsg. Von Moltmann, Teil 1: Karl Barth, Heinrrich Barth, Emil Brunner, Chr. Kaiser Verlag, München 1962. Teil 2: Rudolf Bultmann, Friedrich Gogarten, Eduard Thurneysen, Chr. Kaiser Verlag, München 1967.

, Umkehr zur Zukunft, München 1970.

, Die ersten Freigelassenen der Schopfung, Versuche über die Freude an der Freiheit und das Wohlegefallen am Spiel, München 1971. 

, Erfahrungen theologischen Denkens, München, 1999. , Zukunft der Schöpfung. , Gott im Projekt der modernen Welt, München, 1997.

MONDIN, B., "Creazione”, in Dizionario dei concetti biblici del nuovo testamento, Bologna 2000.

MUNDLE, W., "Venire", in Dizionario dei concetti biblici del nuovo testamento, EDB, Bologna, 2000.

NOBILE, M., Teologia dell'Antico testamento.

PANNENBERG, W., Systematic theology, vol. II, Edinburg,1994.

QUEIRUGA, A. T., Recuperar a criação, 36-37.

RENGSTORF, K. H., "Gesù Cristo" in Dizionario dei concetti biblici del nuovo testamento, Bologna.

RORDORF, W., "Sabado", in Diccionario patristico y de la antigüedad cristiana, $2^{\circ}$ vol. Salamanca, 1998.

STUDER, B., "Creación", in Diccionario patristico y de la antigüedad cristiana, $1^{\circ}$ vol. Salamanca 1998. 508-511.

TILLICH, P., Systematische Theologie, I Chicago,1979.

TORRANCE, T., T, F, Space, time and incarnation, Edinburg, 1997.

Maria Freire da Silva

Doutora em Teologia Dogmática pela Universidade Gregoriana, Vice-coordenadora do Programa de Pós-graduação, Professora de Teologia/PUC/SP.

Artigo Recebido em 14/11/2011 Artigo Aprovado em 16/12/2011 